\title{
Prevalence and risk factors of Appendicitis at Surgery Department of a Tertiary Care Hospital in Pakistan
}

\author{
LARAIB ZAFAR ${ }^{1}$, KIRAN MAQBOOL ${ }^{2}$, MAJ UZMA JAVED GUL ${ }^{3}$, ISHFAQ AHMAD KHAN ${ }^{4}$, ARSHID MAHMOOD $^{5}$ \\ ${ }_{1,2}$ Demonstrator Biochemistry, Poonch Medical College, Rawalakot \\ ${ }^{3}$ Classified Surgical Specialist, Combined Military Hospital, Rawalpindi \\ ${ }^{4}$ Department of Surgery Barnsely Hospital, Barnsley, England \\ ${ }^{5}$ Associate Professor of Surgery, Mohi ud Din Islamic Medical College, Mirpur Azad Kashmir \\ Corresponding Author: Dr. Kiran Maqbool \\ Email Address: kiranmaqbool946@gmail.com, Cell No: +92 3349523852
}

\begin{abstract}
ABSTARCT
Background: Appendicitis needs immediate surgical intervention based on indication in the pediatric age group. Among high-risk young children, the prevalence of pre-existing perforation ranges from $30 \%$ to $75 \%$.

Aim: To investigate the prevalence and risk factors for appendicitis in the inpatient surgical department.

Place and Duration: Study was conducted at surgical department of Combined Military Hospital, Rawalakot for the period of six months from October 2020 to March 2021.

Materials and Methods: A single-center cross-sectional study was conducted on 102 patients with acute appendicitis diagnosed and confirmed by Ultrasonography among the patients admitted to the surgical department during October 2020 to March 2021. Pretested questionnaire were used to collect and record the necessary information.

Results: The sample size of 102 patients had 61 (60\%) males and 41 (40\%) were females. Appendicitis patients were divided into four age groups: $10-19$ years 16 (15.7\%), 20-29 years 19 (32.35\%), 30-39 years 15 (14.7\%), 40 49 years $14(13.7 \%)$, and 50-59 years 7 (.6.8 \%). The male-to-female ratio was 3:2. (60\%, $40 \%)$. The most common complaints are abdominal pain (100\%), vomiting (55.12\%), and fever (87.21\%). Based on histopathological diagnosis, the categorical distributions of appendicitis were Acute Appendicitis (48.10\%), Lymphoid Hyperplasia (25.50\%), and Resolving Appendicitis (47.05\%).

Conclusion: The prevalence of acute appendicitis is more common in males especially in the age group of 20-29 years based on histological diagnosis.
\end{abstract}

Keywords: Appendicitis, Cross-sectional Study

\section{INTRODUCTION}

Appendicitis is still a common reason for urgent surgical intervention in children, and early appendectomy has long been recommended to reduce the risk of appendicular perforation. The influence of age and gender on the time to perforation in acute appendicitis has not been thoroughly studied ${ }^{1}$. The most suspected disorder in patients with urgent abdominal pain is acute appendicitis. In children, acute appendicitis is the common indicator for abdominal surgery ${ }^{2-4}$. The common male to female ratio is $(1.4: 1)^{4}$. Vomiting, nausea, and localized pain consecutively in the right lower quadrant was present in $33 \%$ of affected children with abdominal pain. Delayed/atypical symptoms could be seen in young children $^{5-7}$. Among high-risk young children, the prevalence of pre-existing perforation ranges from 30\% to $75 \%{ }^{8}$. An intra-abdominal abscess is an important complication of perforated appendicitis that increases the morbidity proportion ${ }^{9}$. Timely diagnosis of acute appendicitis is the challenging phase for the practitioner before the occurrence of complications ${ }^{10}$.

Reginald Heber Fits first reported the clinical diagnostic criteria as a classical signs and symptoms of acute appendicitis as a disease entity ${ }^{11}$ in 1886. Still, acute appendicitis is the most common acute surgical condition of the abdomen in all ages, and it is obviously a common disease in surgical practice ${ }^{12}$. Even after more than 120 years since its first depiction, this common surgical disease remains a diagnostic problem and can perplex the majority of clinicians. Delay in diagnosis increases morbidity, mortality, and management costs, as well as the risk of a destructive surgical approach. Despite being so common, its diagnosis remains difficult ${ }^{13}, 14$, resulting in a negative appendectomies rate of $20-40 \%$. Despite advanced diagnostic modalities, the diagnosis is primarily clinical. To make an early diagnosis of appendicitis, various protocols have been introduced and tested by different researchers, including the Lidverg, Fenyo, Christian, Ohman, and Alvarado scoring system ${ }^{15}$. The study's goal was to discover the prevalence and risk factors for appendicitis in the inpatient surgical department.

\section{MATERIALS AND METHODS}

This single-centered cross-sectional study was carried out on 102 patients admitted to the surgery department diagnosed with appendicitis symptoms and confirmed by Ultrasonography during October 2020 to March 2021. Pretested questionnaire was used to collect and record the necessary information. Patient demographic details such as name, gender, age, symptoms, and laboratory analysis were completed in the pretested questionnaire. Data were entered and analyzed in SPSS version 20. The confidence interval was $95 \%$ along with perforate and acute appendicitis proportion as expressed in \%age. Clinical features and laboratory analysis was made based on appendectomy indications. Ultrasound was conducted on all the patients. Specimen were examined and intraoperative findings were recorded. 
Study Design and Setting; In Pakistan, a facility-based cross-sectional study was carried out in surgical department of Combined Military Hospital, Rawalakot. Participants in the study were enrolled during October 2020 and March 2021. Performa was created, which included all of the patient's socio-demographic information, clinical presentation, and scoring system, as well as the on-table findings. The information was entered and analyzed in SPSS $\vee 20$. The research was carried out at tertiary care hospital in Pakistan, in the Department of Surgery.

Inclusion and Exclusion Criteria: All acute appendicitis cases admitted to the center, as well as all patients who underwent emergency surgery. Patients who refused surgery and those who did not have surgery were excluded from the study.

\section{RESULTS}

The sample size of 102 patients had 61 (60\%) males and 41 (40\%) were females. Appendicitis patients were divided into four age groups: $10-19$ years $16(15.7 \%), 20-$ 29 years $19(32.35 \%)$, 30-39 years 15 (14.7\%), 40-49 years $14(13.7 \%)$, and $50-59$ years 7 (.6.8 \%). The maleto-female ratio was $3: 2$. (60\%, $40 \%)$. The most common complaints are abdominal pain (100\%), vomiting $(55.12 \%)$, and fever (87.21\%). Based on histopathological diagnosis, the categorical distributions of appendicitis were Acute Appendicitis (48.10\%), Lymphoid Hyperplasia (25.50\%), and Resolving Appendicitis (47.05\%). Figure 1 shows the age distribution of appendicitis patients.

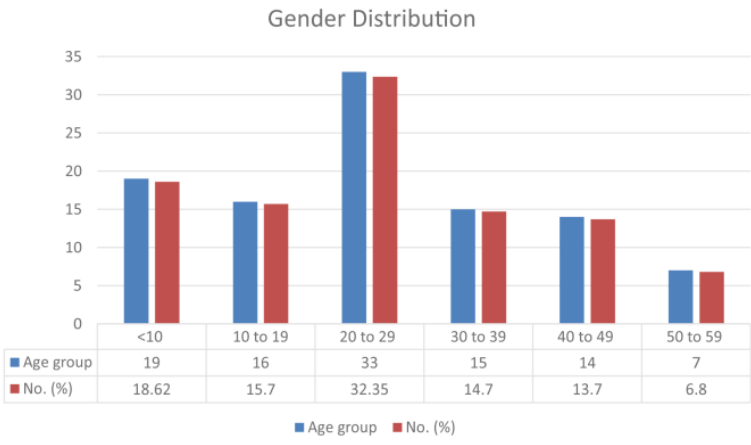

Figure 1. Appendicitis patients age wise distribution

From Figure 1, The most common age for appendicitis was found to be $20-29$ years old (32.35\%), followed by $10-19$ years old $16(15.7 \%)$, and $31-40$ years old 15 (14.7\%), 41-50 14 (13.7\%), 51-60 7 (6.8\%). Proportion of the Male patients was more as compared to Females i.e. (60.00\%) and (40.00\%) as shown in Table 1. The most common presenting complaint was abdominal pain $(100 \%)$, followed by fever $(87.21 \%)$ and vomiting (87.21\%). (55.12\%) as shown in Figure 2.

Table 1: Gender wise Distribution of the Appendicitis patients

\begin{tabular}{|l|l|}
\hline Gender & $\mathbf{N}(\%)$ \\
\hline Male & $61(60)$ \\
\hline Female & $41(40)$ \\
\hline Total & $102(100)$ \\
\hline
\end{tabular}

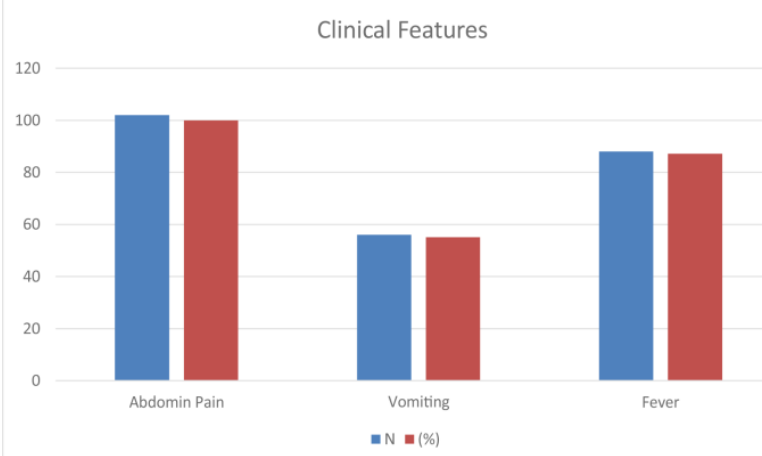

Figure 2: Patient distribution based on the most common diagnoses. Displaying a clinical feature

Based on histopathological diagnosis, the categorical distributions of appendicitis were Acute Appendicitis (48.10\%), Lymphoid Hyperplasia (25.50\%), and Resolving Appendicitis (47.05\%) as shown in Table 2.

Table 2. The patient distribution based on histpathological diagnosis.

\begin{tabular}{|l|l|}
\hline Diagnosis & No. (\%) \\
\hline Lymphoid Hyperplasia & $26(25.50)$ \\
\hline Acute Appendicitis & $49(48.10)$ \\
\hline Resolving Appendicitis & $27(47.07)$ \\
\hline Total & $102(100)$ \\
\hline
\end{tabular}

\section{DISCUSSION}

One of the most common symptoms of patients seeking medical attention is abdominal pain. Acute appendicitis is the most common cause of acute abdominal pain, and it can be difficult to distinguish appendicitis from other disorders, especially in young preverbal children ${ }^{16-20}$. To reduce the morbidity and mortality associated with delayed diagnosis and its complications, early and accurate diagnosis of acute appendicitis is required. On the other hand, reducing the number of unnecessary appendectomies is critical. Acute appendicitis diagnosis is still a difficult task for surgeons. A negative rate of appendectomies ranging from $20 \%$ to $40 \%$ is not uncommon in the surgical literature ${ }^{21}$. The rate of negative appendectomies in this study was 19\%. The percentage of normal appendectomies varies between series, ranging from $83.3 \%$ to $100 \%{ }^{22-24}$.

The observed rate of negative appendectomies was $17 \%$. In a prospective study of 215 adults and children, the use of the Alvarado score reduced an unusually high false positive appendectomies rate of $44 \%$ to $14 \%$. For the entire modern era of surgery, many surgeons believed that a maximum of $15-20$ percent negative appendectomies were acceptable15. The removal of normal appendices is expected to reduce perforation rates and consequent mortality. Unnecessary appendectomies, on the other hand, pose long-term risks to patients12. In or study, Appendicitis patients were divided into four age groups: $10-19$ years 16 (15.7\%), 2029 years $19(32.35 \%), 30-39$ years $15(14.7 \%), 40-49$ years $14(13.7 \%)$, and $50-59$ years $7(.6 .8 \%)$. The maleto-female ratio was $3: 2$. (60\%, $40 \%)$. The most common 
complaints are abdominal pain (100\%), vomiting (55.12\%), and fever (87.21\%). Based on histopathological diagnosis, the categorical distributions of appendicitis were Acute Appendicitis (48.10\%), Lymphoid Hyperplasia (25.50\%), and Resolving Appendicitis (47.05\%).

\section{CONCLUSION}

The most common age for appendicitis was 20-29, and males were affected more than females in histological diagnosis, with acute appendicitis being the most common.

\section{REFERENCES}

1. Augustin T, Cagir B, VanderMeer TJ. Characteristics of perforated appendicitis: effect of delay is confounded by age and gender. J Gastrointestinal Surg. 2011;15(7):1223.

2. Hasbahçeci $M$, Erol $C$, Törü $M$, Şeker M. Effect of surgeon's judgement on the diagnosis of acute appendicitis. Turkish $\mathrm{J}$ Surg/Ulusalcerrahidergisi. 2014;30(1):22

3. Addiss DG, Shaffer N, Fowler BS, Tauxe RV. The epidemiology of appendicitis and appendectomy in the United States. Am J Epidemiol. 1990;132:91025.

4. Hall MJ, DeFrances CJ, Williams SN, Golosinskiy A, Schwartzman A. National Hospital Discharge Survey: 2007 summary. Natl Health Stat Report. 2010;(29):1-20, 24.

5. Davenport M. Acute abdominal pain in children. BMJ. 1996;312:498-501.

6. Horwitz JR, Gursoy M, Jaksic T, Lally KP. Importance of diarrhea as a presenting symptom of appendicitis in very young children. Am J Surg. 1997;173:80-2.

7. Irish MS, Pearl RH, Caty MG, Glick PL. The approach to common abdominal diagnosis in infants and children. PediatrClin North Am. 1998:45:72972.

8. Stefanutti G, Ghirardo V, Gamba P. Inflammatory markers for acute appendicitis in children: are they helpful. $J$ Pediatr Surg. 2007;42:773-6.

9. Bansal S, Banever GT, Karrer FM, Partrick DA Appendicitis in children less than 5 years old: influence of age on presentation and outcome. Am $\mathrm{J}$ Surg. 2012;204:1031-5.

10. Marzuillo P, Germani C, Krauss BS, Barbi E. Appendicitis in children less than five years old: A challenge for the general practitioner. World J Clin Pediatrics. 2015;4(2):19.
11. Fitz RH. Perforating inflammation of the vermiform appendix with special reference to its early diagnosis and treatment Am J Med Sci 1886; 92:32-46.

12. Schwartz SI, Shires GT, Spencer Fe. Principles of Surgery. 6th ed. New York: McGraw-Hill Inc; 1994.p. 130718.

13. Wilcox RT, Willims L W. Have the evaluation and treatment of acute appendicitis changed with new technology Surg Clin N Am 1997; 77: 1355-70.

14. Izbicki J R, Knoefel W T, Wilker $0 \mathrm{~K}$, Mandelkow H K, Muller K, Siebeck M.

15. Accurate diagnosis of Acute Appendicitis: Analysis of 686 patients. Eur Journ Surg 1992; 158:227-31

16. Kulik DM, Uleryk EM, Maguire JL. Does this child have appendicitis? A systematic review of clinical prediction rules for children with acute abdominal pain. J Clin Epidemiol. 2013;66:95-104.

17. Bansal S, Banever GT, Karrer FM, Partrick DA Appendicitis in children less than 5 years old: influence of age on presentation and outcome. Am $\mathrm{J}$ Surg. 2012;204:1031-5.

18. Pogorelić Z, Biočić M, Jurić I, Milunovic KP, Mrklic I. Acute appendicitis as a complication of varicella. Acta Medica (Hradec Králové). 2012;55:150-2.

19. Pogorelić Z, Stipić R, Druzijanić N, Perko Z, Grandic L, et al. Torsion of epiploic appendage mimic acute appendicitis. Coll Antropol. 2011;35:1299-302.

20. Perko Z, Bilan K, Pogorelić Z, Tomic S, Vilovic K, Krnic D, et al. Acute appendicitis and ileal perforation with a toothpick treated by laparoscopy. Coll Antropol. 2008;32:307-9.

21. Macklin CP, Radcliffe GS, Merei JM, and Stringer MD. A prospective evaluation of modified Alvarado scores for acute appendicitis in Children. Ann R Coli Surg Eng11997; 79:203-205

22. Riber C, Tonnesen H, Am A, Bjerregaard B. Observer variation in the assessment of the histopathologic diagnosis of acute appendicitis. Scand J Gastroenterol1999; 34(1): 46-49.

23. Mills S, (cd.) Sternberg's Diagnostic Surgical Pathology. 4th ed, vol 2, Lippincott Williams and Wilkins, p. 1522.

24. Chang FC, Hogle HH, Welling DR. The fate of negative appendix. Am J Surg 1973; 126: 752-754 